\title{
PEMANFAATAN CITRA LANDSAT 8 OLI UNTUK KLASIFIKASI TUTUPAN LAHAN DI TAMAN NASIONAL GUNUNG MERBABU
}

\section{Utilization of Landsat 8 Operational Land Imager (OLI) for land cover classification in Gunung Merbabu National Park}

\author{
Diyanti Isnani Siregar ${ }^{1}$, Adnin Musadri Asbi $^{2}$ \\ ${ }^{I}$ Program Studi Rekayasa Kehutanan, Institut Teknologi Sumatera \\ Jl. Terusan Ryacudu, Kabupaten Lampung Selatan, Lampung, Indonesia, 35365 \\ Email: diyanti.siregar@rh.itera.ac.id \\ ${ }^{2}$ Program Studi Perencanaan Wilayah dan Kota, Institut Teknologi Sumatera \\ Jl. Terusan Ryacudu, Kabupaten Lampung Selatan, Lampung, Indonesia, 35365 \\ Email:adnin.asbi@pwk.itera.ac.id
}

Diterima: 12 Agustus 2020, Direvisi: 14 September 2020, Disetujui: 16 September 2020

DOI: $10.31849 /$ forestra.v15i2.4731

\begin{abstract}
Gunung Merbabu National Park (TNGMb) is a conservation area with a high level of biodiversity. Information on land cover is very important in making ecological management policies in conservation areas. Proven Remote Sensing technology produces precise information on land cover in a time and cost-effective manner. This study uses Landsat 8 imagery in TNGMb land cover classification process. Maximum Likelihood approach is used because it uses a probability calculation basis. A configuration matrix table between training data and reference data is made to test the accuracy of land cover classification. Reference data refers to Google Earth Pro high-resolution imagery. Results showed that the most extensive land cover type was secondary dryland forest with total of 23393 pixels classified as equivalent to 2113.54 hectares $(34.5 \%$ of the total classification area. The open area, built-up area, and rice field/vegetable garden each have an area of $12.08 \mathrm{Ha}$; $11.02 \mathrm{Ha}$; and $170.96 \mathrm{Ha}$, of which part of the area is in enclaved areas within the TNGMb area. The accuracy test shows the Kappa Coefficient of $86.25 \%$, User's Accuracy Average, Ground Truth Average, and Overall Accuracy respectively 89.62\%; 85.42\%; and 88.33\%. Overall Accuracy shows that $88.33 \%$ of the total pixels represent each classification correctly.
\end{abstract}

Keywords: Landsat 8 OLI, land cover classification, Maximum Likelihood, remote sensing

\begin{abstract}
ABSTRAK
Taman Nasional Gunung Merbabu (TNGMb) merupakan kawasan konservasi dengan tingkat keanekaragaman hayati yang tinggi. Informasi mengenai tutupan lahan sangat penting dalam pengambilan kebijakan pengelolaan ekologi di kawasan konservasi. Teknologi Penginderaan Jauh telah teruji menghasilkan informasi yang tepat tentang tutupan lahan dengan cara yang hemat waktu dan biaya. Penelitian ini menggunakan citra Landsat 8 dalam proses klasifikasi tutupan lahan TNGMb. Pendekatan Maximum Likelihood digunakan karena pendekatan ini menggunakan dasar perhitungan probabilitas. Tabel confussion matrix antara training data dan data referensi dibuat untuk uji akurasi
\end{abstract}


klasifikasi tutupan lahan. Data referensi mengacu pada citra resolusi tinggi Google Earth Pro. Hasil penelitian menunjukkan jenis tutupan lahan yang paling luas adalah hutan lahan kering sekunder dengan total 23393 piksel terklasifikasi setara dengan 2113,54 Ha (34,5\% dari total area klasifikasi). Area terbuka, area terbangun, dan sawah/kebun sayur memiliki luasan masing-masing sebesar 12,08 $\mathrm{Ha} ; 11,02 \mathrm{Ha}$; dan 170,96 Ha, dimana sebagian luasan terdapat di wilayah enclave di dalam kawasan TNGMb. Uji akurasi menunjukkan Kappa Coefficient 86,25\%, User's Accuracy Average, Ground Truth Average, dan Overall Accuracy masing-masing sebesar 89,62\%; 85,42\%; dan 88,33\%. Overall Accuracy menunjukkan $88,33 \%$ dari keseluruhan piksel mewakili tiap klasifikasi dengan benar.

Kata kunci: citra Landsat 8 OLI, klasifikasi tutupan lahan, Maximum Likelihood, penginderaan jauh

\section{PENDAHULUAN}

Ketersediaan pengetahuan mengenai tutupan lahan yang andal dan terkini sangat penting dalam banyak kegiatan seperti perencanaan, pengelolaan, pemantauan dan pemutakhiran. Tutupan lahan suatu wilayah tertentu memberikan informasi yang berperan sebagai elemen penting dalam pengambilan kebijakan terkait perubahan lingkungan di tingkat nasional maupun global. Teknologi penginderaan jauh memungkinkan kita untuk memantau dinamika permukaan bumi oleh berbagai satelit observasi bumi. Kemajuan teknik Penginderaan Jauh bersama dengan data pengecekan di lapangan terbukti menghasilkan informasi yang tepat tentang tutupan lahan dengan cara yang hemat biaya (Khalil \& Saad-ul-Haque, 2018).

Kelengkapan dan keakuratan yang dihasilkan oleh penginderaan jauh dipengaruhi oleh data citra yang digunakan.
Untuk menghasilkan informasi mengenai penutup lahan yang akurat, dalam penelitian ini digunakan data yaitu citra Landsat 8. Keunggulan citra Landsat 8 adalah dapat merekam wilayah di permukaan bumi dengan lebih luas/cakupannya lebih besar, memiliki resolusi spasial, temporal dan radiometrik yang bagus, pada setiap topografi yang ada di permukaan bumi dibedakan dengan warna, dan setiap identifikasi yang ada di permukaan bumi dapat dibedakan dengan panjang gelombang yang ada di citra Landsat 8 .

Interpretasi citra adalah kegiatan mengkaji objek pada foto udara atau citra untuk menilai pentingnya obyek tersebut (Sutanto, 1994). Interpretasi citra dilakukan melalui 3 (tiga) tahapan yaitu deteksi, identifikasi dan analisis. Deteksi merupakan pengenalan awal dengan melihat foto udara atau citra secara keseluruhan. Identifikasi 
merupakan pembacaan ciri-ciri (spektral, spasial, dan temporal) dari setiap objek. Analisis merupakan penguraian dan pengklasifikasian data hasil identifikasi sehingga menghasilkan bentuk tabel, grafik dan atau peta tematik.

Kelengkapan dan keakuratan yang dihasilkan oleh penginderaan jauh dipengaruhi oleh data citra yang digunakan. Untuk menghasilkan informasi mengenai penutup lahan yang akurat, dalam penelitian ini digunakan data yaitu citra Landsat 8. Keunggulan citra Landsat 8 adalah dapat merekam wilayah di permukaan bumi dengan lebih luas/cakupannya lebih besar, memiliki resolusi spasial, temporal dan radiometrik yang bagus, pada setiap topografi yang ada di permukaan bumi dibedakan dengan warna, dan setiap identifikasi yang ada di permukaan bumi dapat dibedakan dengan panjang gelombang yang ada di citra Landsat 8. Interpretasi citra adalah kegiatan mengkaji objek pada foto udara atau citra untuk menilai pentingnya obyek tersebut (Sutanto, 1994). Interpretasi citra dilakukan melalui 3 (tiga) tahapan yaitu deteksi, identifikasi dan analisis. Deteksi merupakan pengenalan awal dengan melihat foto udara atau citra secara keseluruhan. Identifikasi merupakan pembacaan ciri-ciri (spektral, spasial, dan temporal) dari setiap objek. Analisis merupakan penguraian dan pengklasifikasian data hasil identifikasi sehingga menghasilkan bentuk tabel, grafik dan atau peta tematik.

Data citra yang digunakan dalam penginderaan jauh sangat mempengaruhi tingkat akurasi hasil klasifikasi tutupan lahan suatu wilayah. Penelitian ini menggunakan citra Landsat 8 OLI karena memiliki keunggulan yaitu cakupan perekaman wilayah permukaan bumi yang lebih luas, resolusi spasial, temporal dan radiometrik yang baik, perbedaan warna pada setiap keadaan muka bumi, dan memiliki perbedaan panjang gelombang untuk identifikasi permukaan bumi (Septiani et al., 2019)

Penelitian berlokasi di Taman Nasional Gunung Merbabu (TNGMb). TNGMb adalah salah satu taman nasional di Pulau Jawa yang yang memiliki luas 5.820,49 Hektar di Kabupaten Semarang, Kabupaten Boyolali, dan Kabupaten Magelang (Balai Taman Nasional Gunung Merbabu, 2014). TNGMb memiliki 
keanekaragaman hayati yang tinggi.

Kawasan hutan di TNGMb menjadi habitat alami berbagai spesies yang dilindungi.

Penelitian ini bertujuan untuk melakukan klasifikasi tutupan lahan di Taman Nasional Gunung Merbabu dengan $\begin{array}{llll}\text { memanfaatkan citra Landsat } & 8 & \text { OLI. }\end{array}$ Informasi klasifikasi tutupan lahan yang diperoleh dapat digunakan sebagai masukan bahan kajian ekologi di Taman Nasional Gunung Merbabu.

\section{METODE PENELITIAN}

Penelitian berlokasi di Taman Nasional Gunung Merbabu (TNGMb), Provinsi Jawa Tengah. TNGMb dipilih sebagai lokasi penelitian karena karakteristik wilayahnya yang unik, berbentuk menjari dan berbatasan langsung dengan beberapa kabupaten dengan penduduk yang padat. TNGMb secara geografis terletak pada $110^{\circ} 32^{\prime} \mathrm{BT}-110^{\circ}$ 48'BT dan $7^{0} 38^{\prime}$ LS $-7^{0} 48^{\prime}$ LS dengan ketinggian tempat $\pm 600-3.142$ meter di atas permukaan air laut. Luas wilayah penelitian $\pm 5.820,49$ Ha. Kegiatan penelitian yang mencakup pengumpulan data, kerja lapangan, dan analisis data. Alat penelitian yaitu GPS, DNRGPS, Personal
Coumputer (PC), kamera digital, dan perangkat lunak ArcGIS 10.3. Bahan penelitian yaitu Peta Rupa Bumi Indonesia (.shp), Peta batas administrasi TNGMb (.shp), dan Citra Satelit Landsat 8 OLI/TIRS yang memiliki path/row: 120/65. Informasi tutupan lahan diperoleh dari hasil identifikasi Citra Satelit Landsat 8 OLI/TIRS pada path/row 120/65. Untuk memudahkan proses interpretasi, citra yang dipilih adalah citra yang bersih dari awan. Penelitian ini menggunakan citra dengan tanggal akuisisi 18 September 2015 yang sama sekali tidak tertutupi awan pada daerah penelitian yaitu Taman Nasional Gunung Merbabu. Interpretasi secara visual pada layar komputer dilakukan untuk menentukan jenis-jenis tutupan lahan yang ditunjukkan objek pada citra. Proses dilanjutkan dengan klasifikasi multispektral secara terbimbing (supervised classification) pada perangkat lunak ArcGIS 10.3. Pendekatan Kemungkinan Maksimum (Maximum Likelihood) pada tools yang disediakan oleh ArcGIS digunakan karena pendekatan ini menggunakan dasar perhitungan probabilitas. Pendekatan ini mengelaskan piksel sebagai objek tertentu bukan karena 
jarak euklidiannya, melainkan oleh bentuk, ukuran, dan orientasi sampel pada feature space (Danoedoro, 2012)

Penentuan jenis tutupan lahan mengacu pada standar penentuan jenis tutupan lahan level II (resolusi spasial 30 100) yang dikeluarkan oleh Badan Standardisasi Nasional Indonesia (Badan Standardisasi Nasional, 2010). Uji validasi hasil klasifikasi dilakukan dengan membuat tabel kesalahan (confussion matrix) antara training data dan data referensi. Dalam penelitian ini, data referensi mengacu pada citra resolusi tinggi yang tersedia dalam Google Earth Pro.

\section{HASIL DAN PEMBAHASAN}

Citra Landsat 8 dengan tanggal akuisisi 18 September 2015 yang diunduh melalui laman USGS digunakan untuk identifikasi dalam pembuatan peta tutupan lahan di Taman Nasional Gunung Merbabu beserta daerah sekitarnya. Tanggal akuisisi tersebut dipilih dikarenakan minimnya tutupan awan pada area sekitar Taman Nasional Gunung Merbabu.

\section{Identifikasi Tutupan Lahan}

Interpretasi citra secara visual dilakukan dalam penelitian ini dengan mempertimbangkan 7 kunci interpretasi yang mencirikan karakteristik objek yang tampak pada citra berdasarkan bentuk, ukuran, rona/warna, tekstur, pola, lokasi dan asosiasi.

Komposit band 543 (warna semu) pada Landsat 8 digunakan untuk mempermudah klasifikasi daerah yang bervegetasi maupun tidak bervegetasi. Dalam proses identifikasi tutupan lahan ini, diperlukan pemilihan Training Sample untuk penentuan jenis tutupan lahan. Training sample dipilih dengan membuat polygon pada tiap sample area yang memenuhi kriteria suatu tipe tutupan lahan. Proses identifikasi juga dilakukan dengan bantuan visualisasi gambar wilayah Taman Nasional Gunung Merbabu dan sekitarnya yang tersedia dalam Google Earth dengan tanggal perekaman 6 Agustus 2014. Tabel 1 di bawah ini menyajikan beberapa hasil identifikasi jenis tutupan lahan yang dihasilkan melalui proses training sample. 


\section{Klasifikasi Tutupan Lahan}

Proses klasifikasi terbimbing tutupan lahan dilakukan menggunakan Maximum Likelihood Classifier (MLC) tools, yang tersedia di dalam perangkat lunak ArcGIS 10.3. MLC merupakan salah satu metode yang paling banyak digunakan pada berbagai penelitian yang menggunakan data penginderaan jauh, khususnya dalam proses klasifikasi terbimbing tutupan lahan. Secara sederhana, MLC mendistribusikan pikselpiksel yang memiliki probabilitas paling tinggi terhadap suatu kelas tertentu yang menggambarkan suatu tipe tutupan lahan (Mei et al., 2016). Dalam proses identifikasi citra Landsat 8, band komposit warna semu
(543) diterapkan sebelum proses klasifikasi. Tutupan lahan di wilayah penelitian diklasifikasikan (menggunakan klasifikasi level II SNI) dan dibagi ke dalam 7 jenis tutupan lahan yaitu: hutan lahan kering primer, hutan lahan kering sekunder, hutan campuran, semak belukar/rumput, sawah/kebun sayur, area terbangun, dan area terbuka (Badan Standardisasi Nasional, 2010). Dalam penelitian ini, bayangan juga dimasukkan ke dalam daftar klasifikasi untuk menghitung luas piksel yang tidak teridentifikasi jenis tutupan lahannya. Secara keseluruhan, peta jenis tutupan lahan yang dihasilkan dapat dilihat pada Gambar 1.

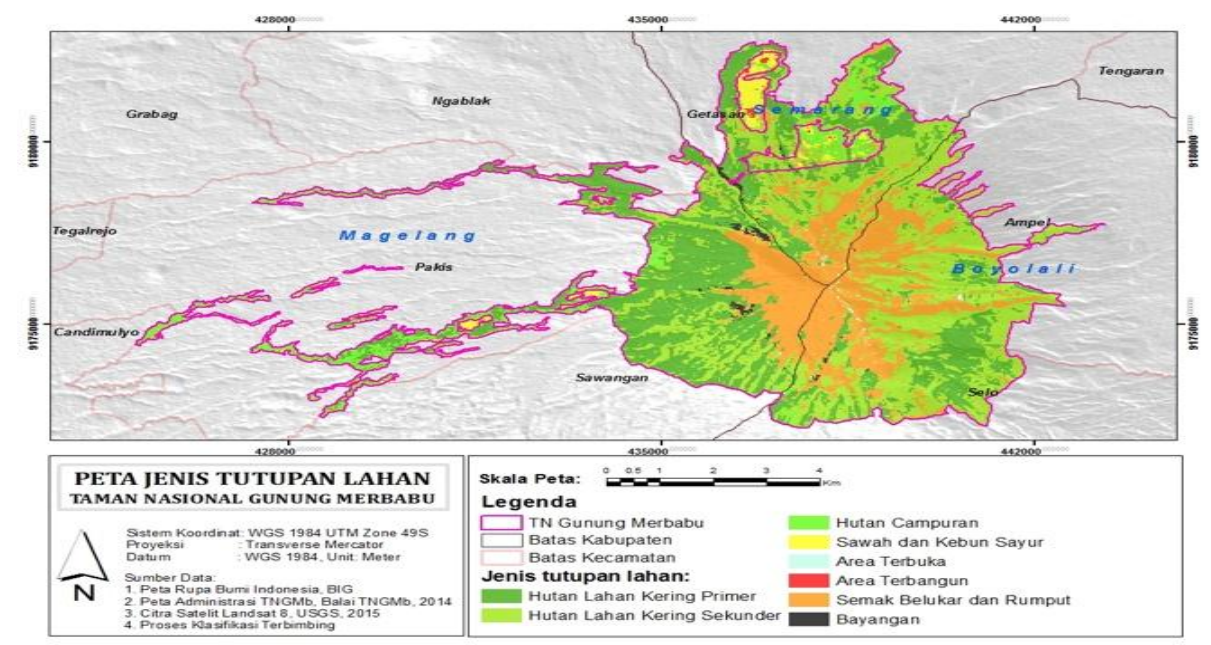

Gambar 1. Peta Jenis Tutupan Lahan Taman Nasional Gunung Merbabu Tabel 1 Hasil Identifikasi Jenis Tutupan Lahan di TNGMb 


\begin{tabular}{|c|c|c|}
\hline $\begin{array}{c}\text { Tutupan/ } \\
\text { Penggunaan } \\
\text { Lahan } \\
\end{array}$ & $\begin{array}{l}\text { Contoh Training Sample Area } \\
\text { (Komposit Band 543) }\end{array}$ & Deskripsi Interpretasi \\
\hline $\begin{array}{l}\text { Hutan } \\
\text { bervegetasi } \\
\text { padat }\end{array}$ & & $\begin{array}{l}\text { Berwarna merah tua, bertekstur kasar, } \\
\text { berasosiasi dengan lereng curam. }\end{array}$ \\
\hline $\begin{array}{l}\text { Hutan } \\
\text { bervegetasi } \\
\text { sedang }\end{array}$ & & $\begin{array}{l}\text { Berwarna merah, lebih terang } \\
\text { dibandingkan hutan bervegetasi padat, } \\
\text { berlokasi dekat dengan jalur } \\
\text { pendakian. }\end{array}$ \\
\hline $\begin{array}{c}\text { Area } \\
\text { terbangun }\end{array}$ & & $\begin{array}{l}\text { Berwarna biru-kehijauan (cyan), pola } \\
\text { beraturan, bertekstur kasar, ber- } \\
\text { asosiasi dengan jalan, sawah, kebun } \\
\text { dan lereng datar hingga landai. }\end{array}$ \\
\hline $\begin{array}{l}\text { Area } \\
\text { terbuka }\end{array}$ & & $\begin{array}{l}\text { Berwarna biru-kehijauan (cyan), } \\
\text { tekstur halus, di daerah pegunungan } \\
\text { berasosisasi dengan puncak gunung. }\end{array}$ \\
\hline $\begin{array}{c}\text { Hutan } \\
\text { campuran }\end{array}$ & & 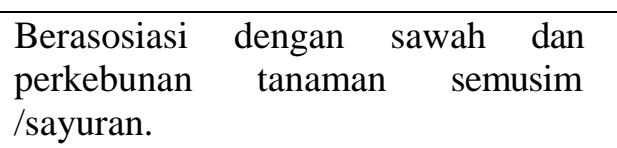 \\
\hline Tubuh air & & $\begin{array}{l}\text { Berwarna biru-kehijauan (cyan) gelap, } \\
\text { membentuk jalur yang berliku-liku, } \\
\text { berlokasi di lereng yang tidak curam. }\end{array}$ \\
\hline $\begin{array}{l}\text { Semak } \\
\text { belukar dan } \\
\text { rumput }\end{array}$ & & $\begin{array}{l}\text { Berwarna cokelat terang, bertekstur } \\
\text { halus, berasosiasi dengan area terbuka, } \\
\text { di TNGMb kebanyakan berlokasi di } \\
\text { area sekitar puncak. }\end{array}$ \\
\hline $\begin{array}{l}\text { Sawah dan } \\
\text { kebun sayur }\end{array}$ & & $\begin{array}{l}\text { Pola beraturan, berasosisasi dengan } \\
\text { permukiman, di lereng datar hingga } \\
\text { landai, dan sebagian hutan campuran }\end{array}$ \\
\hline Bayangan & & $\begin{array}{l}\text { Berwarna hitam, terdapat pada lahan } \\
\text { yang berlereng sangat curam }\end{array}$ \\
\hline
\end{tabular}


Gambar 1 menunjukkan hasil klasifikasi 8 jenis tutupan lahan termasuk bayangan yang juga diikutsertakan untuk meningkatkan akurasi klasifikasi. Area puncak Gunung Merbabu didominasi oleh vegetasi semak belukar dan rumput. Hal tersebut dapat dilihat dari warna jingga pada peta. Jenis penutup semak belukar dan

rumput adalah objek paling sering terbakar saat terjadi kebakaran hutan dan lahan di TNGMb (Asbi, 2017). Lereng gunung bagian barat yang termasuk dalam Kecamatan Sawangan dan Pakis bervegetasi padat (hutan lahan kering primer) ditandai dengan warna hijau tua pada peta. Daerah enclave bagian utara didominasi oleh sawah dan kebun sayur (warna kuning) serta sebagian terdapat warna merah pada peta yang menunjukkan tutupan lahan area terbangun (permukiman). Sebagaimana dituliskan secara detail pada Tabel 2 bahwa jenis tutupan lahan yang paling luas adalah hutan lahan kering sekunder dengan total 23393 piksel terklasifikasi yang setara dengan 2113,54 Ha, atau sekitar 34,5\% dari total area klasifikasi yang mencapai 6124,58 Ha. Tabel 2 juga menunjukkan bahwa area terbuka, area terbangun, dan sawah/kebun sayur memiliki luasan masing- masing sebesar 12,08 Ha; 11,02 Ha; dan 170,96 Ha, dimana sebagian luasan terdapat di wilayah enclave di dalam kawasan TNGMb.

\section{Uji Akurasi Hasil Klasifikasi Citra}

Pengujian hasil klasifikasi citra perlu dilakukan untuk menilai keakuratan dari sampel uji pada setiap kelas. Uji akurasi dilakukan dengan membandingkan hasil klasifikasi dengan keadaan sebenarnya di lapangan (ground truth). Proses ini mengacu pada gambar yang disediakan oleh Google Earth Pro (tanggal perekaman 6 Agustus 2014) karena memiliki tingkat kejelasan dan kedetailan yang cukup tinggi. Perbandingan untuk uji klasifikasi ini dilakukan dengan membuat tabel Error Matrix dimana penghitungan akurasi dilakukan dengan cara yang berbeda-beda (User's Accurracy, Ground Accurracy, Overall Accurracy dan Kappa Coefficient) dapat dilakukan (Kerle et al., 2001). Tabel error matrix sebagai hasil proses uji klasifikasi terhadap 8 kelas tutupan lahan dapat dilihat pada Tabel 3. Dari tabel tersebut terlihat bahwa overall accuracy dari hasil klasifikasi tutupan lahan di TNGMb didapatkan sebesar 88,33\%. 
Hasil dari uji akurasi menunjukkan

bahwa Kappa Coefficient didapatkan sebesar 86,25\%, dimana User's Accuracy Average, Ground Truth Average, dan Overall Accuracy masing-masing didapatkan sebesar $89,62 \%$; 85,42\%; dan 88,33\%. Dari hasil-hasil yang didapatkan tidak terlihat adanya perbedaan signifikan antar nilai tersebut.

Tabel. 2 Hasil Klasifikasi Jenis Tutupan Lahan/Penggunaan Lahan di TNGMb

\begin{tabular}{lccc}
\hline Jenis tutupan lahan & Jumlah piksel & Luas & Persentase \\
$($ Ha) & & $(\%)$
\end{tabular}

Hutan lahan kering

21631

1953,21

31,89 primer

Hutan lahan kering

23393

2113,54

34,51

sekunder

\begin{tabular}{lccc}
\hline Hutan campuran & 6173 & 555,82 & 9,08 \\
\hline Sawah dan kebun & 1896 & 170,96 & 2,79
\end{tabular}
sayur

Semak belukar dan

14155

1270,22

20,74 rumput

\begin{tabular}{lccc}
\hline Area terbuka & 141 & 12,08 & 0,20 \\
\hline Area terbangun & 123 & 11,02 & 0,18 \\
\hline Bayangan & 436 & 37,73 & 0,62 \\
\hline & & & $\mathbf{6 1 2 4 , 5 8}$ \\
\hline
\end{tabular}


Overall Accuracy menunjukkan bahwa 88,33\% dari keseluruhan piksel mewakili tiap klasifikasi dengan benar. Ground Truth Average menunjukkan tingkat keakuratan sampel di lapangan yang sebenarnya mencakup 85,42\%. Kappa Coefficient menjelaskan besaran nilai benar dari kesalahan dalam matrix diantara true agreement dan change agreement (Lillesand et al., 2004). Kappa Coefficient diatas mengilustrasikan bahwa $86,25 \%$ klasifikasi yang telah diobservasi lebih baik dibandingkan dengan klasifikasi yang dihasilkan dari perubahan.

Tabel. 3. Error Matrix 8 Kelas Tutupan Lahan Hasil Proses Klasifikasi

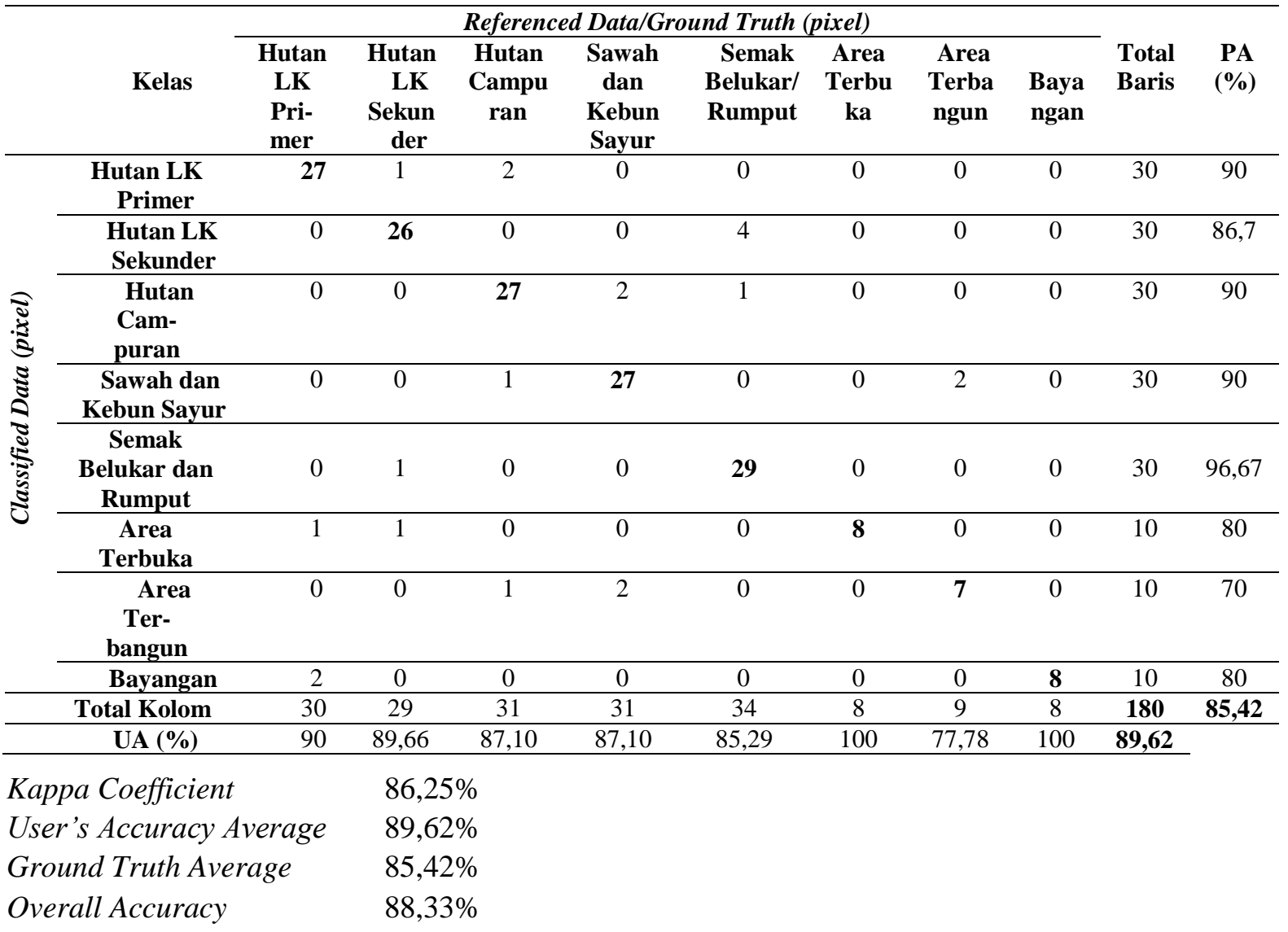

\section{KESIMPULAN DAN SARAN}

\section{A. Kesimpulan}

Hasil klasifikasi 7 jenis tutupan lahan yaitu hutan lahan kering primer, hutan lahan kering sekunder, hutan campuran, semak belukar/rumput, sawah/kebun sayur, area terbangun, dan area terbuka. Bayangan juga diikutsertakan untuk meningkatkan akurasi klasifikasi. Kappa Coefficient didapatkan sebesar 86,25\%, dimana User's Accuracy Average 
89,62\%, Ground Truth Average 85,42\%, dan Overall Accuracy 88,33\%. Dari hasilhasil yang didapatkan tidak terlihat adanya perbedaan signifikan antar nilai tersebut. Overall Accuracy menunjukkan bahwa 88,33\% dari keseluruhan piksel mewakili tiap klasifikasi dengan benar. Sehingga dapat disimpulkan bahwa hasil klasifikasi tersebut akurat dan informasi klasifikasi tutupan lahan TNGMb dari penelitian ini dapat digunakan karena telah memenuhi syarat akurasi overall $>85 \%$ oleh USGS.

\section{B. Saran}

$$
\text { Peta klasifikasi tutupan lahan }
$$
berguna dalam memberikan informasi jenis-jenis tutupan lahan yang ada di kawasan TNGMb. Informasi jenis tutupan lahan dapat dijadikan pertimbangan oleh instansi terkait dalam memutuskan kebijakan yang berkaitan dengan ekologi kawasan TNGMb.

\section{DAFTAR PUSTAKA}

Asbi, A. M. (2017). Emergency Response and Evacuation Route Planning in Case of Wildfires in Gunung Merbabu National Park Indonesia. University Of Twente.

Badan Standardisasi Nasional. (2010). Klasifikasi Penutup Lahan. In Sni 7654 (Issue 2010).
Balai Taman Nasional Gunung Merbabu. (2014). Zonasi Taman Nasional Gunung Merbabu (Dokumen Revisi Zonasi).

Danoedoro, P. (2012). Pengantar Penginderaan Jauh Digital. CV. ANDI.

Kerle, N., Janssen, L. L. F., \& Huurneman, G. C. (eds. . (2001). Principles of Remote Sensing ITC (Educational Textbook Series) (3rd ed.). ITC.

Khalil, R. Z., \& Saad-ul-Haque. (2018). InSAR coherence-based land cover classification of Okara, Pakistan. The Egyptian Journal of Remote Sensing and Space Science, 21, S23-S28. https://doi.org/10.1016/j.ejrs.2017.08.0 05

Lillesand, T. M., Kiefer, R. W., \& Chipman, J. W. (2004). Remote Sensing and Image Interpretation (5th ed.). John Wiley \& Sons, Inc.

Mei, A., Manzo, C., Fontinovo, G., Bassani, C., Allegrini, A., \& Petracchini, F. (2016). Assessment of land cover changes in Lampedusa Island (Italy) using Landsat TM and OLI data. African Earth Science, 122, $15-24$

Septiani, R., Citra, I. P. A., \& Nugraha, A. S. (2019). Perbandingan Metode Supervised Classification dan Unsupervised Classification terhadap Penutup Lahan di Kabupaten Buleleng. Jurnal Geografi, 16(2), 9096. 
Sutanto. (1994). Penginderaan Jauh.

Gadjah Mada University Press. 